\title{
Infiltração de água e resistência do solo à penetração em sistemas de cultivos integrados e em área de pastagem degradada
}

Leonnardo Cruvinel Furquim ${ }^{1}$, Epitácio José de Souza ${ }^{2}$, Nelmício Furtado da Silva ${ }^{2}$, Daniel Noe Coaguila Nuñez ${ }^{2}$, Juliana Silva Rodrigues Cabral ${ }^{2}$, José Mateus Kondo Santini ${ }^{2}$, Beatriz Caetano da Silva Leão ${ }^{2}$, Luís Fernando Stone ${ }^{3}$

${ }^{1}$ Universidade Federal de Goiás - UFG, GO. ${ }^{2}$ Faculdade Rio Verde - UniBras, GO. ${ }^{3}$ Embrapa Arroz e Feijão - EMBRAPA, DF. E-mail: leonnardolp@hotmail.com

\section{Resumo}

O objetivo deste estudo foi quantificar a infiltração de água e a resistência à penetração em um Latossolo Vermelho cultivado com diferentes sistemas de uso da terra e em área de pastagem degradada. As áreas de estudo estão localizadas no município de Rio Verde (GO), onde foram avaliados sete tratamentos: T1Degradado; T2 - Pasto adubado; T3 - Convencional; T4 - Integração lavoura-floresta (ILF); T5 - Integração pecuária-floresta (IPF); T6 - Integração lavoura-pecuária-floresta (ILPF feno) e T7 - Integração lavourapecuária-floresta (ILPF silagem). Foram determinadas as curvas de velocidade de infiltração de água e os respectivos valores de velocidade de infiltração básica (VIB) para as áreas em estudo. A infiltração da água no solo foi determinada "in situ" pelo método do infiltrômetro de anéis duplos e empiricamente por meio de modelos propostos por Kostiakov e Kostiakov-Lewis. A resistência do solo à penetração, até a profundidade de $0,3 \mathrm{~m}$, foi realizada com o uso de penetrômetro de impacto. A maior infiltração em relação ao tempo ocorreu no tratamento T7. Os maiores valores de velocidade de infiltração básica ocorreram no tratamento T5. O modelo proposto por Kostiakov apresentou maior ajuste aos dados de velocidade de infiltração obtidos no campo. A menor resistência do solo à penetração é proporcionada pela diversidade de espécies nos tratamento T4. Os diferentes sistemas de manejo para recuperação de pastagem degradada influenciaram nos indicadores de qualidade do solo estudados, porém há necessidade de novos estudos para adequação das taxas de lotação nos sistemas integrados, para não retornar ao cenário de degradação.

Palavras-chave: eucalipto; integração lavoura-pecuária-floresta; forrageira; Latossolo Vermelho.

\section{Water infiltration and soil resistance to penetration in integrated crop systems and in degraded pasture areas}

\begin{abstract}
The objective of this study was to quantify water infiltration and resistance to penetration in a Latossolo Vermelho Distrófico (Typic Haplustox) cultivated with different land use systems and in a degraded pasture area. The studied areas are located in Rio Verde, state of Goiás (Brazil), where seven treatments were evaluated: T1 - Degraded; T2 - Fertilized pasture; T3 - Conventional; T4 - Crop-forest integration system (CFI); T5 - Livestock-forest integration system (LFI); T6 - crop-livestock-forest integration system (CLFI - hay); and T7 - crop-livestock-forest integration system (CLFI - silage). The water infiltration speed curves and the respective basic infiltration rate (BIR) values for the areas under study were determined. The infiltration of water into the soil was determined "in situ" by the double ring infiltrometer method and empirically through models proposed by Kostiakov and Kostiakov-Lewis. The soil resistance to penetration, up to a depth of $0.3 \mathrm{~m}$, was performed using an impact penetrometer. The greatest infiltration in relation to time occurred in treatment T7. The highest values of BIR occurred in treatment T5. The model proposed by Kostiakov showed greater adjustment to the infiltration speed data obtained in the field. The lower resistance of the soil to penetration is provided by the diversity of species in the T4 treatment. The different management systems for recovering degraded pastures influenced the soil quality indicators
\end{abstract}


studied, but there is a need for further studies to adjust the stocking rates in integrated systems in order not to return to the degradation scenario.

Keywords: crop-livestock-forest integration; eucalyptus; forage; Typic Haplustox .

\section{Introdução}

A estratégia de ocupação do Cerrado pela atividade de pecuária foi bem diferente daquela encontrada na agricultura de grãos. A evolução da pecuária na região centrou, quase que exclusivamente, na utilização intensa do fator terra em detrimento da intensificação no uso de capital. Desse modo, a pecuária no Cerrado foi tradicionalmente caracterizada pelo extrativismo, com uso limitado de insumos no sistema de produção (FURQUIM et al., 2018).

A expansão da agricultura no Cerrado ao longo dos anos vem afetando negativamente as propriedades físicas, químicas e biológicas do solo. Esse fato é agravado pelo manejo inapropriado e uso inadequado do solo, em que não são levadas em consideração suas características físicas para implantação do sistema de cultivo (SILVA et al., 2014).

Os agrossistemas vêm se tornando uma das alternativas de menor impacto na produção de alimentos e de madeira, além de permitir a manutenção e/ou menor impacto sobre as propriedades do solo, harmonizando a cultura local ao desenvolvimento agrícola (COUTO et al., 2016). Segundo Maria et al. (2017), no Brasil existem cerca de 67,8 milhões de hectares de áreas aptas para serem utilizadas por diversos modelos de sistemas integrados, sem a necessidade de abertura de novas áreas com vegetação nativa.

O aumento da intensidade de atividades agrícolas em sistemas de produção de baixa sustentabilidade tem afetado a dinâmica de água no solo, em função do aumento da densidade do solo, resistência do solo à penetração e da redução da porosidade e estabilidade de agregados, como resultado do aumento do trafego de máquinas, redução da diversificação de culturas, uso de métodos de irrigação pouco eficientes, pisoteio animal e baixos teores de matéria orgânica (SHAH et al., 2017). Dessa forma, tem-se buscado pela sustentabilidade dos processos produtivos, refletindo na implantação de sistemas integrados de produção, os quais proporcionam benefícios, como a preservação da água e do solo.
As pastagens constituem a base da produção de ruminantes no país, permitindo a exploração de sistemas de produção mais estáveis do ponto de vista produtivo e econômico. No entanto, a degradação dessas áreas, em várias regiões brasileiras, tem diminuído a produtividade das pastagens, comprometendo a sustentabilidade e rentabilidade (FREITAS et al., 2016).

A implantação de quaisquer sistemas produtivos traz modificações no ambiente original, especialmente no solo, a fim de propiciar condições necessárias para o estabelecimento e produção das plantas cultivadas. Essas modificações no solo ocorrem nas propriedades físicas, químicas e biológicas, porém, nem sempre essas modificações no solo ocorrem de forma sustentável. Deste modo, torna-se necessário o uso de critérios que possam avaliar de forma correta as condições atuais do solo e, assim, recomendar práticas de manejo que possam reestabelecer, conservar ou aprimorá-las, de forma que permitam um desenvolvimento vegetal mais sustentável.

A resistência à penetração é representada pela força que o solo oferece à penetração de um cone metálico, a qual simula a resistência que o mesmo tem ao crescimento do sistema radicular (SILVA et al., 2016). Segundo Fernandes et al. (2016), a resistência à penetração é uma das propriedades físicas importante para o manejo e estudo da qualidade física dos solos, tendo em vista que essa propriedade se apresenta relacionada a diversos atributos do solo indicadores do grau de compactação. Inicialmente, utilizava-se o limite crítico de $2 \mathrm{MPa}$, no entanto, Moraes et al. (2014) verificaram que em Latossolo Vermelho Distroférrico, esse limite seria adequado apenas para sistemas convencionais e que, para preparo mínimo e sistema plantio direto, esse valor deveria ser ampliado para 3 e 3,5 $\mathrm{MPa}$, respectivamente.

A infiltração é o processo pelo qual a água percola no perfil do solo, através de sua superfície, no sentido vertical descendente. A velocidade desse fenômeno é alta quando o solo 
está seco e tende a diminuir à medida que os poros do solo são preenchidos com água, até que o solo se sature e a velocidade se torne constante, conhecida por taxa de infiltração básica, a qual é influenciada diretamente pelas condições da superfície do solo, como a cobertura do solo, em que esta o protege dos efeitos do impacto das gotas de chuva e do runoff (SILVA et al., 2017), e pelos atributos relacionados com a estruturação do solo, como a distribuição de poros, matéria orgânica, textura e densidade do solo (MARTINS; SANTOS, 2017).

A infiltração de água no solo é considerada um dos mais importantes processos (ZHAO et al., 2013; ZHIPENG, et al., 2018), possui conexão direta com $\mathrm{o}$ abastecimento de aquíferos, manutenção do fluxo nos corpos d'água, além da conservação da água por mais tempo na bacia hidrográfica, o que pode refletir na disponibilidade de água para as coberturas vegetais (MORAIS, 2012).

O uso de modelos matemáticos para delinear o processo de infiltração da água no solo é um dos recursos que facilitam a compreensão do efeito de atributos do solo que influenciam o processo de infiltração (SILVA et al., 2017). Esse processo de saturação pode demorar horas em solos mais argilosos, por conta disso, testes de infiltração podem ser muito demorados e cansativos, levando pesquisadores a estudar metodologias e modelos matemáticos que facilitem a obtenção desse atributo do solo (GOMES FILHO et al., 2018). Podem-se dividir os modelos matemáticos de infiltração de água no solo em duas categorias: empíricos e determinísticos (HABILI; HEIDARPOUR, 2015).
É primordial conhecer a taxa de infiltração da água no solo, pois é um dos parâmetros fundamentais para o eficiente manejo do solo e da água, planejar e delinear sistemas de irrigação e drenagem, além de auxiliar na caracterização da retenção da água e aeração no solo (VILARINHO et al., 2013, RIQUELME et al., 2012).

A hipótese deste estudo é que a diversificação de culturas proporcionada por diferentes sistemas de cultivo integrados melhora a estrutura do solo, influenciando positivamente na resistência do solo à penetração e na taxa de infiltração. Objetivou-se neste estudo quantificar a infiltração de água e a resistência à penetração em um Latossolo Vermelho Distroférrico (LVdf) cultivado com diferentes sistemas de cultivo integrados e em área de pastagem degradada.

\section{Materiais e Métodos}

$O$ estudo foi realizado em áreas localizadas na Fazenda de Ensino, Pesquisa e Extensão FEPE da Faculdade UniBRAS - Rio Verde - GO, na seguinte localização geográfica $17^{\circ} 44^{\prime} 59.22^{\prime \prime S}$ e $50^{\circ} 55^{\prime} 56.78 " \mathrm{O}$, com $765 \mathrm{~m}$ de altitude. O solo predominante das áreas de estudo é classificado como Latossolo Vermelho Distroférrico (LVdf), de textura muito argilosa (SANTOS et al., 2018). O clima da região é classificado como Aw (tropical), com chuva nos meses de outubro a maio, e com seca de junho a setembro. A temperatura média anual é de 20 a $35^{\circ} \mathrm{C}$ e as precipitações variam de 1.500 a $1.800 \mathrm{~mm}$ anuais (SILVA et al., 2017).

Foram avaliados sete tratamentos (Tabela 1), sendo $\mathrm{UA}=$ Unidade animal $=450 \mathrm{~kg}$ de peso vivo: 
Tabela 1. Descrição dos diferentes sistemas de cultivos integrados sobre área de pastagem degradada, Rio Verde - GO, 2019.

\begin{tabular}{|c|c|c|c|}
\hline Tratamento & Manejo & Taxa de lotação & Pastejo \\
\hline T1- Degradado: & $\begin{array}{l}\text { Pastagem em estado de degradação, cultivada } \\
\text { com Urochloa brizantha; com pastejo de animais }\end{array}$ & 1,36 UA ha $^{-1}$ & 507 dias \\
\hline T2 - Pasto adubado & $\begin{array}{l}\text { Recuperação de pastagem degradada por meio da } \\
\text { calagem e adubação de manutenção, sem } \\
\text { preparo de solo, cultivada com Urochloa } \\
\text { brizantha; com pastejo de animais }\end{array}$ & $1,68 \mathrm{UA} \mathrm{ha}^{-1}$ & 507 dias \\
\hline T3 - Convencional & $\begin{array}{l}\text { Preparo convencional do solo*, calagem, } \\
\text { adubação para semeadura de forrageira; com } \\
\text { pastejo de animais }\end{array}$ & 2,05 UA ha ${ }^{-1}$ & 355 dias \\
\hline $\begin{array}{l}\text { T4- Integração } \\
\text { lavoura-floresta (ILF) }\end{array}$ & $\begin{array}{l}\text { Preparo do solo convencional*, calagem e } \\
\text { adubação para o cultivo de eucalipto, consorciado } \\
\text { nos entre renques com quatro ciclos de } \\
\text { sucessões: ciclo } 1 \text { - cultivo de melancia; ciclo } 2 \text { - } \\
\text { cultivo alternado de banana e abacaxi; ciclo } 3 \text { - } \\
\text { mandioca de mesa e ciclo } 4 \text { - milho verde }\end{array}$ & S.P.A & S.P.A \\
\hline $\begin{array}{l}\text { T5 - Integração } \\
\text { pecuária-floresta (IPF) }\end{array}$ & $\begin{array}{l}\text { Preparo do solo convencional*, calagem e } \\
\text { adubação para o cultivo de eucalipto, } \\
\text { consorciados nos entre renques com forrageira; } \\
\text { com pastejo de animais }\end{array}$ & $2,68 \mathrm{UA} \mathrm{ha}^{-1}$ & 507 dias \\
\hline $\begin{array}{l}\text { T6 - Integração } \\
\text { lavoura-pecuária- } \\
\text { floresta (ILPF feno) }\end{array}$ & $\begin{array}{l}\text { Preparo do solo convencional*, calagem e } \\
\text { adubação para o cultivo de eucalipto, consorciado } \\
\text { nos entre renques com forrageira para fenação; } \\
\text { dois ciclos de fenação e um ciclo com pastejo de } \\
\text { animais após o restabelecimento da altura de } \\
\text { corte da forrageira }\end{array}$ & $4,15 \cup \mathrm{Uha}{ }^{-1}$ & 157 dias \\
\hline $\begin{array}{l}\text { T7- Integração lavoura- } \\
\text { pecuária-floresta (ILPF } \\
\text { silagem) }\end{array}$ & $\begin{array}{l}\text { Preparo do solo convencional*, calagem e } \\
\text { adubação para o cultivo de eucalipto, consorciado } \\
\text { nos entre reques com sorgo consociado com } \\
\text { forrageira para ensilagem; dois ciclos de fenação } \\
\text { e um ciclo com pastejo de animais após o } \\
\text { restabelecimento da altura de corte da forrageira }\end{array}$ & $3,26 \mathrm{UA} \mathrm{ha}^{-1}$ & 157 dias \\
\hline
\end{tabular}

Cada tratamento tem aproximadamente 1,3 hectares de área e foram implantados em novembro de 2017. O manejo da fertilidade solo seguiu as recomendações propostas por Sousa e Lobato (2004), para cada cultivo em solos de Cerrado. Nos tratamentos T4, T5, T6 e T7 realizou-se o plantio de mudas do clone de eucalipto AEC-2111 (E. camaldulensis $x \quad E$. grandis) $\times E$. urophylla) com espaçamento entre plantas de 1,5 metros, em linhas simples espaçadas por 22 metros, formando os renques para os diversos consórcios. A forrageira semeada nos tratamentos T3, T5, T6 e T7 foi o híbrido BRS RB331 Ipyporã, (Urochloa brizantha $\mathrm{x}$ Urochloa ruziziensis) com a densidade de semeadura de $3 \mathrm{~kg}$ de sementes puras viáveis SPV ha ${ }^{-1}$. Os ciclos de sucessão do sistema T4 foram: ciclo 1 - cultivo da melancia híbrida Combat (175) (Citrullus lanatus); ciclo 2 - cultivo alternado de banana (Musa sp., subgrupo Prata) e abacaxi Pérola (Ananas comosus), ciclo 3 mandioca (Manihot esculenta Crantz) e ciclo 4 milho verde (Zea mays ). O sistema T7 utilizou no consórcio com a pastagem o sorgo forrageiro BRS655 (Sorghum bicolor).

Os testes de infiltração de água no solo e de resistência à penetração foram realizados em novembro de 2019. Nessa época, a altura média das plantas de eucalipto era de 4,6 m. A metodologia empregada na determinação da infiltração de água no solo foi a do infiltrômetro de anéis duplos (BERNARDO et al., 2019). Ela consiste de um anel externo com 0,20 m de diâmetro e $0,40 \mathrm{~m}$ de altura e um anel interno 
com 0,10 $\mathrm{m}$ de diâmetro e $0,40 \mathrm{~m}$ de altura, inseridos no solo a uma profundidade de aproximadamente $0,20 \mathrm{~m}$, com uma régua fixada na borda do anel interno, projetada até tocar a superfície do solo, para medir a lâmina de água.

Os tempos em minutos de cada leitura foram: $0,1,2,5,10,15$ e 30 minutos a iniciar do instante zero, e, posteriormente, com repetições a cada 30 minutos até o tempo total de duração de cada teste de 155 minutos. Os testes foram realizados até que a taxa de infiltração, observada no anel interno, tornou-se aproximadamente constante com o tempo. 0 critério adotado neste trabalho para condição de taxa de infiltração constante foi quando o valor de leitura da carga de água no anel interno se repetiu, pelo menos, três vezes.

Após a coleta dos dados, foram elaboradas curvas de infiltração segundo os modelos utilizados. A qualidade do ajuste dos modelos foi avaliada por meio de regressões não lineares entre os valores estimados e os valores médios observados em cada tratamento estudado, juntamente com os respectivos coeficientes de determinação. Foram determinadas as curvas de infiltração acumulada e velocidade de infiltração de água no solo que descreve o volume de água que penetra no solo em função do tempo, por meio das seguintes equações (WALLER; YITAYEW, 2016):

$$
\begin{gathered}
\mathrm{I}=\mathrm{a} \mathrm{T}^{\mathrm{n}} \\
\mathrm{V}=\mathrm{V}_{0} \mathrm{~T}^{\mathrm{b}}
\end{gathered}
$$

em que: $\mathrm{I}=$ infiltração acumulada, em $\mathrm{mm}$; $\mathrm{V}=$ velocidade de infiltração de água no solo pelo método de Kostiakov, em $\mathrm{mm} \mathrm{h}^{-1}$; a e $\mathrm{n}=$ constantes que dependem do solo (adimensionais) e $\mathrm{T}=$ tempo, em horas.

A velocidade de infiltração da água no solo foi determinada "in situ" através do método do infiltrômetro de anel e empiricamente por meio de modelos proposto por Kostiakov (1932) e Kostiakov-Lewis (1945), conforme citado por Bernardo, Soares e Mantovani (2006), demonstrados a seguir:

$$
\begin{gathered}
\mathrm{V}=\mathrm{V}_{\mathrm{i}} \cdot \mathrm{t}^{\mathrm{b}} \\
\mathrm{V}=\mathrm{V}_{\mathrm{i}} \cdot \mathrm{t}^{\mathrm{b}}+\mathrm{V}_{\mathrm{f}} \cdot \mathrm{t}
\end{gathered}
$$

em que: $V$ = velocidade de infiltração de água no solo após o empoçamento da água na superfície do solo, $\mathrm{cm} \mathrm{h}^{-1} ; V_{i}=$ velocidade de infiltração inicial, $\mathrm{cm} \mathrm{h}^{-1} ; V_{f}=$ velocidade de infiltração final, $\mathrm{cm} \mathrm{h}{ }^{-1} ; \mathrm{b}=$ constante de proporcionalidade, dependentes do tipo do solo e da intensidade de precipitação e $t=$ tempo, em horas.

Os testes de infiltração de água no solo foram realizados em cada um dos locais de estudo. $O$ delineamento experimental utilizado foi inteiramente casualizados com três repetições (pseudo-repetições) totalizando 21 testes de infiltração considerando os diferentes sistemas de uso do solo. Nos sistemas integrados a casualização ocorreu entre renques do eucalipto. Foi realizada análise descritiva para comparação da velocidade de infiltração de água no solo das áreas. Para avaliar o desempenho entre os valores da infiltração obtidos em campo e os valores calculados pelos modelos empíricos de Kostiakov e Kostiakov-Lewis para os testes de infiltração foram feitas análises comparativas dos resultados estatisticamente por meio do coeficiente de determinação $\left(R^{2}\right)$.

A resistência do solo à penetração (RSP), até a profundidade de $0,3 \mathrm{~m}$, foi realizada com o uso de penetrômetro de impacto modelo IAA/Planalsucar, descrito por Stolf (1991). Para conversão dos números de impactos para a RSP com esse equipamento aplicou-se a seguinte equação (Equação 5):

$$
\mathrm{RSP}=5,6+6,89 \times\left(\frac{\mathrm{N}}{\mathrm{D}-\mathrm{A}} \times 10\right) \times 0,0981
$$

Em que: RSP = resistência do solo à penetração ( $\mathrm{MPa}) ; \mathrm{N}=\mathrm{o}$ número de impactos efetuados para a obtenção da leitura; $A$ e $D$ = leituras anteriores (A) e posteriores (D) da realização dos impactos (cm).

A amostragem ocorreu em quatro pontos aleatórios por tratamento. Nos sistemas integrados a aleatorização ocorreu nos entre renques do eucalipto, sendo que cada ponto foi constituído de três subamostras coletadas equidistantes a um metro, em geometria triangular. Os dados convertidos foram avaliados nas camadas de $0-0,10 \mathrm{~m} ; 0,10-0,20 \mathrm{~m}$ e $0,20-0,30$ $\mathrm{m}$.

Concomitantemente ao ensaio de RSP, foi realizada a determinação da umidade volumétrica nos mesmos pontos, nas mesmas camadas do solo. A umidade volumétrica foi determinada com uso de um sensor de umidade do solo modelo Higrow-ESP 32, que é sensor capacitivo controlado por microcontrolador ESP32 (BISWAS; IQBAL, 2018). Para aumentar a acurácia do sensor, foi realizada uma calibração conforme o proposto por Gava et al. (2016).

Para análise estatística foi considerado o delineamento inteiramente casualizados, com 
quatro repetições (pseudo-repetições), conforme Maia et al. (2007). Os dados originais foram submetidos ao teste de normalidade de Kolmogorov - Smirnov ( $p>0,05)$, análise de variância pelo teste $F(p>0,05)$ e, quando significativo, utilizou-se $\mathrm{o}$ teste de Tukey $(p>0,05)$, na análise qualitativa para comparação de média empregando o software $R \quad 3.2 .2$ programa estatístico $R$ para os diferentes testes (R CORE TEAM, 2016).

Tabela 2. Valores de velocidade de infiltração básica (VIB) para os diferentes tratamentos, Rio Verde - GO, 2019.

\begin{tabular}{lc}
\hline Tratamento & Velocidade de infiltração básica (VIB) \\
\cline { 2 - 2 } T1 - Degradado & $\mathrm{mm} \mathrm{h}^{-1}$ \\
T2 - Pasto adubado & $8,0 \mathrm{~b}$ \\
T3 - Convencional & $11,3 \mathrm{ab}$ \\
T4 - ILF & $27,5 \mathrm{ab}$ \\
T5 - IPF & $13,0 \mathrm{ab}$ \\
T6 - ILPF feno & $29,0 \mathrm{a}$ \\
T7 - ILPF silagem & $24,0 \mathrm{ab}$ \\
\hline
\end{tabular}

Médias seguidas de mesma letra na coluna não diferem significativamente entre si segundo teste de Tukey a $5 \%$ de significância.

Segundo a classificação da VIB de Bernardo et al. (2019), sendo: baixa (VIB $<5,0$ $\left.\mathrm{mm} \mathrm{h}^{-1}\right)$; média $\left(5,0 \leq \mathrm{VIB} \leq 15 \mathrm{~mm} \mathrm{~h}^{-1}\right)$; alta $(15 \leq$ VIB $\leq 30 \mathrm{~mm} \mathrm{~h}^{-1}$ ); e muito alta (VIB $>30 \mathrm{~mm} \mathrm{~h}^{-1}$ ), a VIB das áreas estudadas classificou-se como média na maioria dos tratamentos, exceto nos tratamentos T3 - Convencional; T5 - IPF: Eucalipto x Braquiária para pastejo e T6 - ILPF feno, em que a VIB classificou-se como alta (Tabela 2).

Esses resultados corroboram os encontrados por Silva et al. (2014) em um Latossolo Vermelho Distroférrico em Rio Verde $\mathrm{GO}$, que verificaram que mesmo como com o pisoteio de animais e tráfico de máquinas, a capacidade de infiltração de água em um sistema ILPF foi maior que no plantio convencional de culturas anuais (soja/milho). Cabral Filho et al. (2017) encontram valores de $34,9 \mathrm{~mm} \mathrm{~h}^{-1}$ para área de culturas anuais em sistema convencional e 76,8 $\mathrm{mm} \mathrm{h}^{-1}$ para área de ILPF com braquiária consorciada com milho. Silva et al. (2017) encontraram valores de VIB de até $49,5 \mathrm{~mm} \mathrm{~h}^{-1}$ em sistema de preparo convencional, superiores aos observados em sistema plantio direto e Moraes et al. (2020) encontraram valores para VIB de $10,7 \mathrm{~mm} \mathrm{~h}^{-1}$ para pastagem degradada, $31,6 \mathrm{~mm} \mathrm{~h}^{-1}$ para pastagem não degradada, 21,3 $\mathrm{mm} \mathrm{h}^{-1}$ para solo arado, 52,7 unidade para área de floresta e 37,7 unidade para área de pousio. 0

\section{Resultados e Discussão}

Analisando-se a velocidade de infiltração básica (VIB), ou seja, o momento em que a VIB se torna constante, observa-se que o sistema IPF (T5) propiciou maior VIB em relação à pastagem degradada (T1) e não diferiu dos demais tratamentos (Tabela 2). 
Figura 1. Velocidade de infiltração da água no solo obtida em campo pelo método do anel infiltrômetro e os dados estimados pelas equações de Kostiakov e Kostiakov-Lewis para os diferentes tratamentos T1 Degradado; T2 - Pasto adubado; T3 - Convencional; T4 - ILPF: Eucalipto x Fruticultura; T5 - IPF; T6 - ILPF feno; e T7 - ILPF silagem, Rio Verde - GO, 2019.
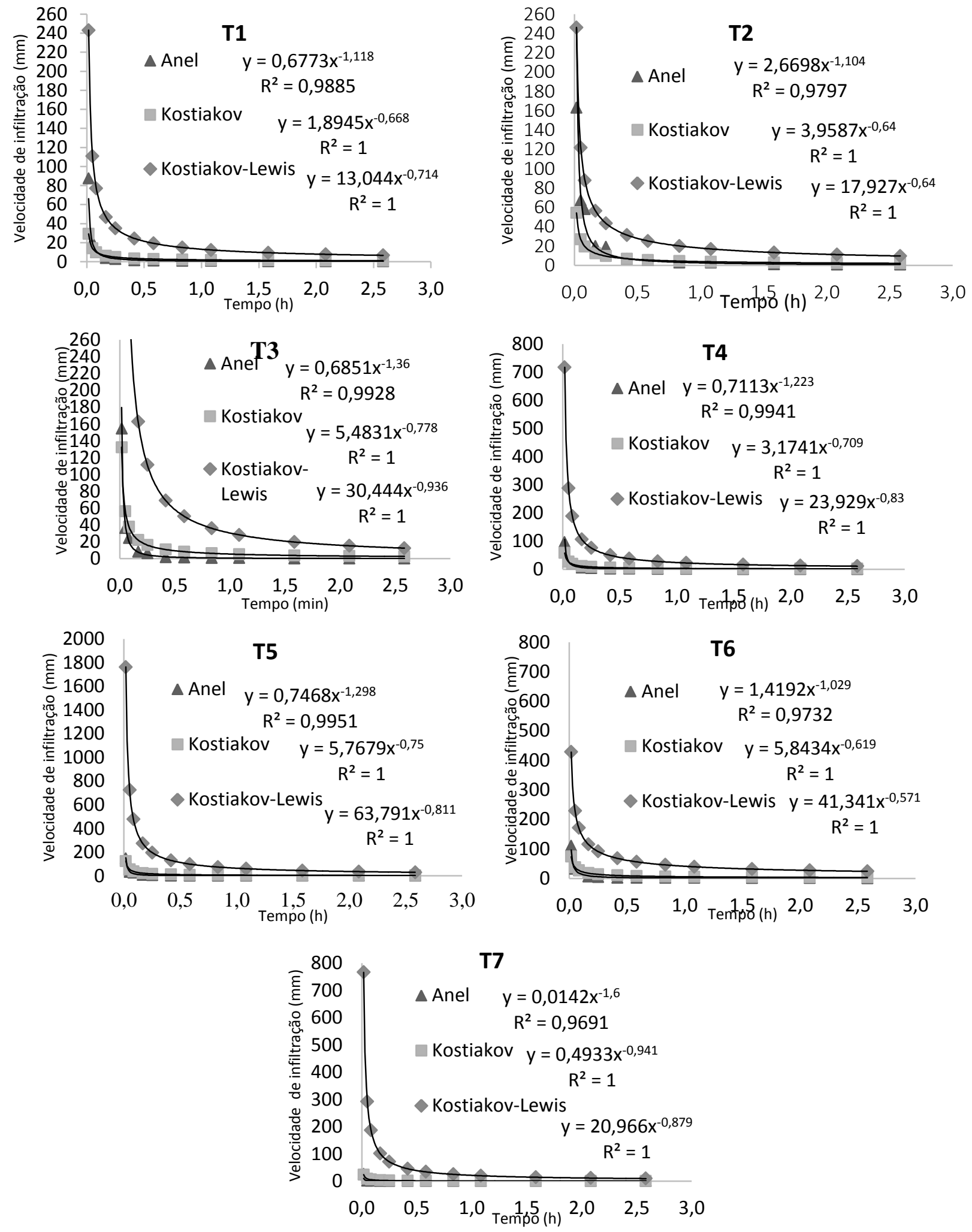

Apesar das pastagens receberem pisoteio animal, o que tenderia a diminuir a capacidade de infiltração da água no solo com o tempo de uso e o manejo inadequado dos mesmos (GONÇALVES; MORAES, 2012), a velocidade de infiltração neste trabalho foi maior nos sistemas T5 com pastejo de animais por mais dias, mostrando uma boa manutenção da qualidade de solo no manejo adotado nesses sistemas de cultivo, pois segundo Silva et al. (2014), Silva 
Filho, (2016), Cabral Filho et al. (2017) e Gomes Filho et al. (2019), a medida da taxa de infiltração da água no solo é considerada um bom indicativo da verificação da sua qualidade física.

Comparando-se as velocidades de infiltração obtidas pelo infiltrômetro de duplo anel com os valores estimados pelas equações de Kostiakov e Kostiakov-Lewis para os diferentes tratamentos observa-se que os valores estimados por Kostiakov são mais próximos daqueles obtidos com o anel infiltrômetro (Figura 1), porém esse modelo tende a subestimar a taxa de infiltração no início do teste, enquanto o modelo de Kostiakov-Lewis superestima os valores iniciais. Santos et al. (2014) observaram que o modelo de Kostiakov teve tendência de subestimar as VIBs e o modelo de KostiakovLewis tendência a superestimar, já Silva et al. (2017) observaram que os modelos propostos por Kostiakov e Kostiakov-Lewis resultaram em melhor estimativa da velocidade de infiltração que o método do anel infiltrômetro.

Cunha et al. (2015) concluíram que a metodologia de Kostiakov expressou melhor o processo de infiltração, porém, ela tende a subestimar a taxa de infiltração no início (Unuigbe et al., 2016).

Segundo Cabral-Filho et al. (2017), em solos característicos do bioma Cerrado, como o Latossolo Vermelho, o modelo empírico de Kostiakov tem-se mostrado comparativo aos demais modelos empregados para estimar a infiltração de água no solo, como o de KostiakovLewis.

Em sistemas de cultivo, a capacidade de infiltração de água é importante para que não haja perda de água. No bioma Cerrado, essa importância é maior ainda devido à grande quantidade de chuvas em um período concentrado. Para Cabral Filho et al. (2017), o comportamento do fluxo de água no solo evidencia o comportamento da água das chuvas e de irrigação no solo. O menor escoamento da chuva e a evidência de maior carga d'água suportada pelo solo são processos que, em solos naturais, ou seja, com ausência ou quase nenhuma interferência antrópica, são satisfatórios, já o escoamento pode ser previsto nos solos com menor VIB, maior compactação e menor porcentagem de macroporosidade.

Vale ressaltar que a relação entre o manejo e a qualidade do solo pode ser avaliada pelo comportamento das propriedades físicas, químicas e biológicas do solo. Além disso, o monitoramento da qualidade do solo pelos atributos físico-hídricos é importante para a manutenção e avaliação da sustentabilidade dos sistemas agrícolas. Neste sentido, considera-se importante fazer um acompanhamento das características físico-hídricas dessas áreas, com a finalidade de se observar o impacto da agricultura no Latossolo Vermelho Distroférrico e demonstrar o estágio de degradação/recuperação das áreas estudadas.

Com relação à resistência do solo à penetração, observa-se que apenas ocorreu alterações significativa dos sistemas de manejo na camada de 0 a $0,10 \mathrm{~m}$, em que o tratamento composto pelo sistema silviagrícola (T4) apresentou a menor média de RSP, 1,62 $\mathrm{MPa}$. Os demais tratamentos não diferiram entre si (Figura 2). 
Figura 2. Resistência do solo à penetração (RSP), em profundidade, cultivado com diferentes sistemas de cultivo integrados e em área de pastagem degradada. Barras horizontais comparam os valores de resistência à penetração, para cada profundidade, pelo teste Tukey (5\%).

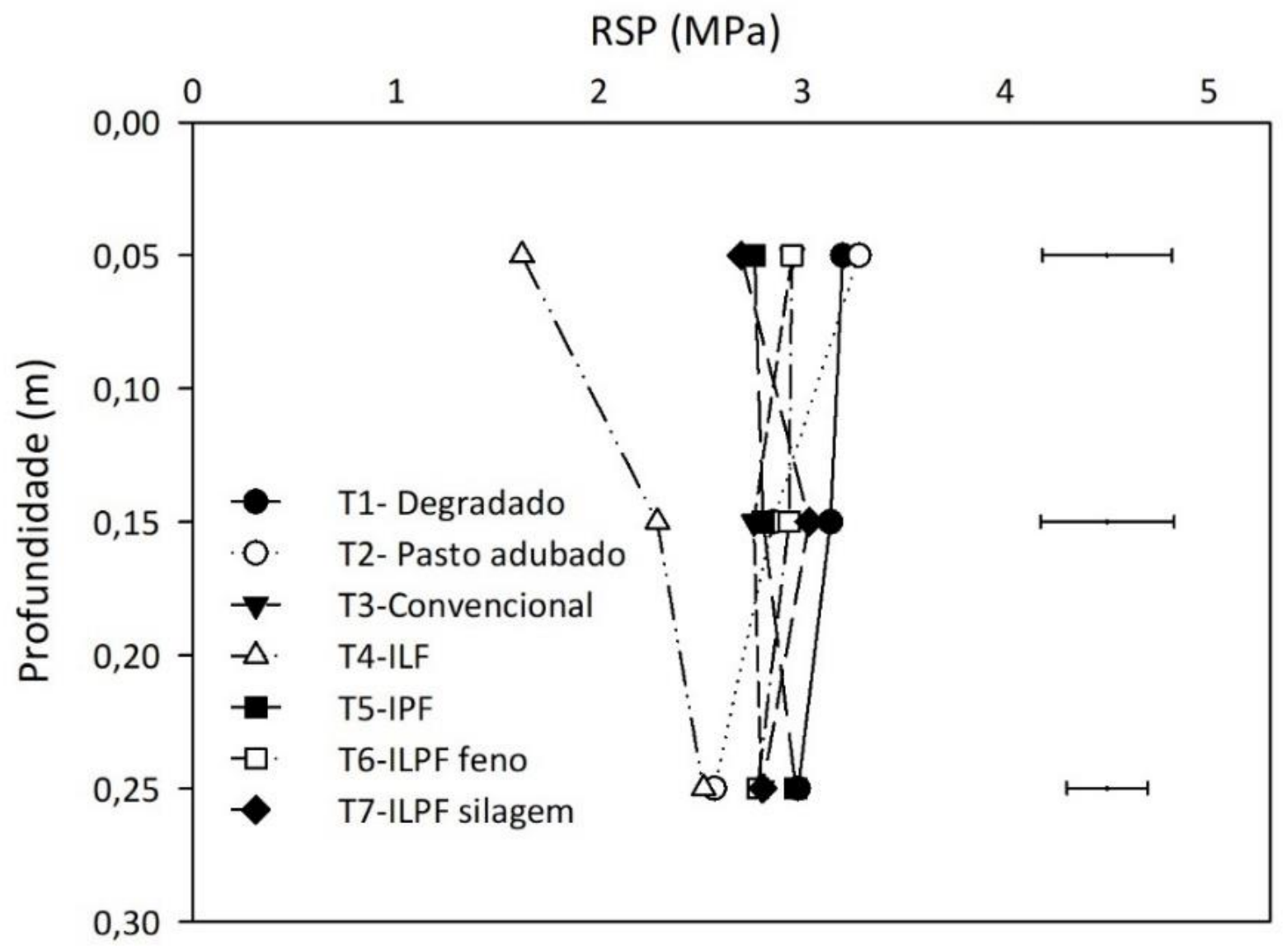

A diversidade de espécies (melancia; banana, abacaxi, mandioca, milho verde, eucalipto) e a não presença de animais, permite entender a redução na RSP. A diversidade de coberturas contribui com o aumento da quantidade de resíduos orgânicos depositados sobre a superfície do solo. Assim, segundo Arevalo-Hernandez et al. (2016), esse acúmulo de biomassa sobre o solo reduz o impacto direto da gota de chuva na degradação do solo, minimizando o efeito da compactação desses solos.

Outra relação da diversidade de espécies com a RPS é que, ao final do ciclo, as raízes das plantas se decompõem e formam-se bioporos que, apesar de representarem pequeno volume em relação ao volume total de poros, são altamente funcionais e reduzem a resistência do solo (COSTA et al., 2016).

Além da ação da matéria orgânica, outro fator é apontado para esse efeito na RPS, a não ocorrência de pastejo de animais na área nesse tratamento. A ação do pisoteio animal afeta diretamente as propriedades físicas do solo, por alterar o seu sistema poroso, com reflexos no movimento de água e ar na camada superficial (BENEVENUTE et al., 2020).

$O$ efeito da presença de animais sobre a RSP nas camadas iniciais $(0-0,10 \mathrm{~m})$ do solo é visualizado na Figura 2, pois todos os tratamentos que receberam pastejo de animais apresentaram valor de RSP sem diferença significativa entre si. Os valores de RSP nos diferentes tratamentos apenas ultrapassaram o limite crítico de 3,0 $\mathrm{MPa}$ (MORAES et al., 2014) na camada de 0 a 0,10 m, com os tratamentos $\mathrm{T} 1$ - pastagem degradada e T2 - pasto adubado, e na camada de 0,10 a 0,20 $\mathrm{m}$, com os tratamentos T1 e T7 - ILPF silagem.

Acreditava-se que nos tratamentos T6 e $\mathrm{T7}$, por ter recebido um pastejo tardio, os valores de RSP seriam diferentes dos demais, o que não ocorreu (Figura 2). Isso pode ser atribuído à intensa movimentação de máquinas para produção de silagem e feno; à redução de matéria orgânica devido à exportação de 
biomassa nessas duas formas de conservar forragem; e pela maior taxa de lotação.

Apenas a produção de feno utiliza em média cinco passadas de máquinas por corte (NERES; AMES, 2015). O intenso tráfego de máquinas utilizado na produção de forragens conservadas, associado a condições inadequadas de água no solo, condiciona a compactação do solo e a degradação das pastagens (BONDI et al., 2020; CASTAGNARA et al., 2015).

A elevada taxa de lotação ou pressão de pastejo é o principal fator de compactação do solo com animais a pasto (COSTA et al., 2012). Os sistemas integrados nas modalidades silvipastoris têm apresentado um efeito localizado de compactação do solo, devido à concentração de animais próximos as espécies arbóreas em virtude do conforto térmico (BORGES et al., 2019; MAGALHÃES et al., 2018).

O teor de água solo não apresentou diferenças significativas entre os diferentes tratamentos (Figura 3).

Figura 3. Umidade volumétrica do solo $\left(\theta_{v}\right)$, em profundidade, cultivado com diferentes sistemas de cultivo integrados e em área de pastagem degradada. Barras horizontais comparam os valores de umidade volumétrica, para cada profundidade, pelo teste Tukey (5\%).

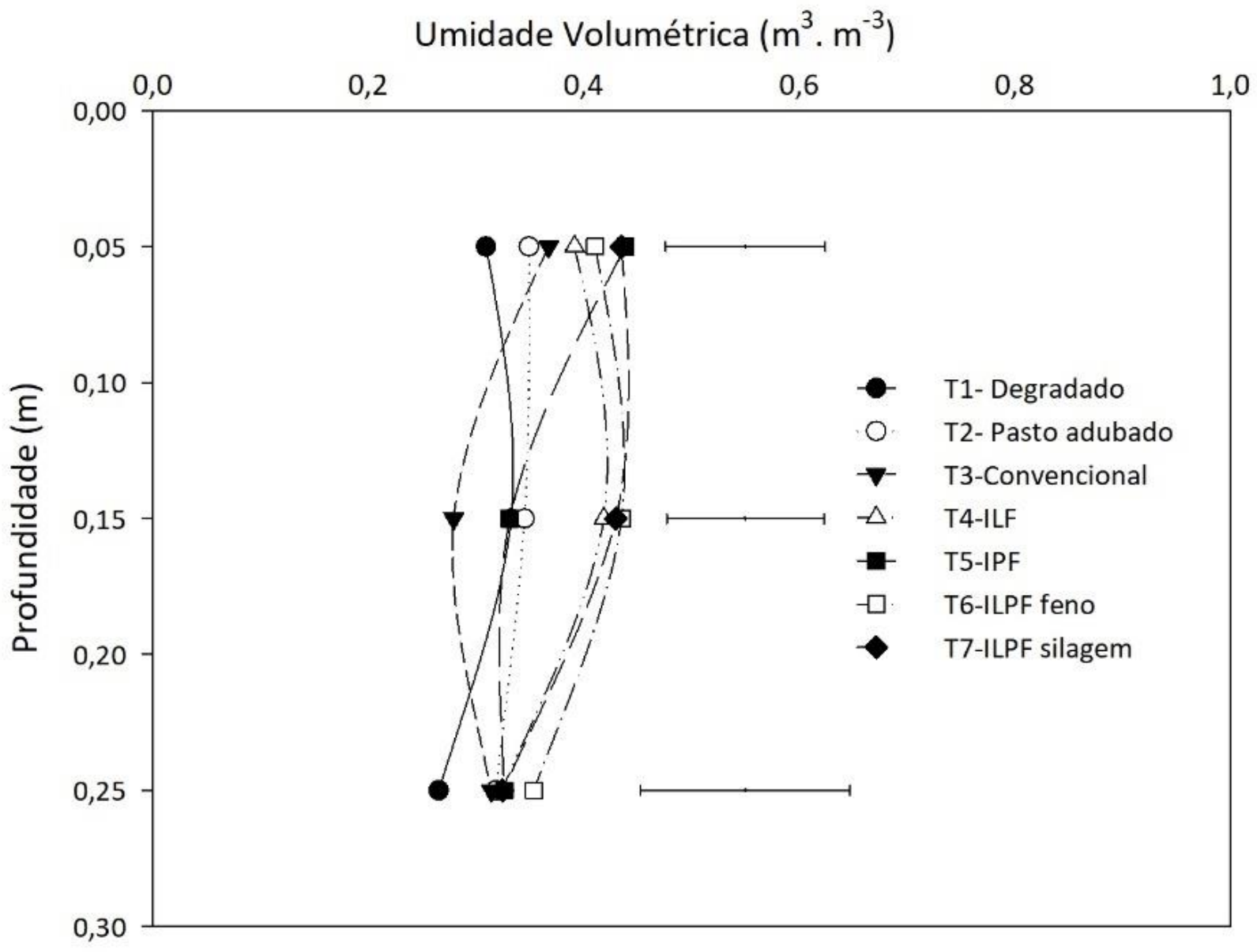

Dias antes das avaliações, a área recebeu precipitações que acumuladas atingiram altura superior a $80 \mathrm{~mm}$, assim a umidade do solo não apresentou diferença significativas em virtude desse fato. Assim, a uniformidade do teor de água no solo não influenciou os resultados da RSP. Bayat et al. (2017) afirmam que, além da dependência de fatores intrínsecos do solo, como textura, estrutura, mineralogia, a RSP é diretamente influenciada pela umidade do solo.

\section{Conclusão}

Nos sistemas de cultivo em que há preparo do solo, a velocidade de infiltração básica tende a ser maior, com destaque para o sistema de integração pecuária-floresta com cultivo de eucalipto consorciado com braquiária para pastejo, e o plantio da braquiária feito com preparo convencional do solo. 
O modelo empírico Kostiakov subestima, em média, os valores das taxas de infiltração no início do processo comparados com os dados obtidos em campo, enquanto o modelo de Kostiakov-Lewis superestima os resultados.

O modelo proposto por Kostiakov ajustase satisfatoriamente aos dados de campo na estimativa da velocidade de infiltração básica.

A pastagem degradada apresenta maiores valores de resistência do solo à penetração e menor velocidade de infiltração em comparação com os sistemas integrados.

A diversidade de espécies e a não presença de animais contribui para menor resistência do solo à penetração no sistema Integração lavoura-floresta.

Há necessidade de novos estudos para adequação das taxas de lotação nos sistemas integrados para não retornar ao cenário de degradação.

\section{Agradecimentos}

Os autores agradecem ao Instituto de Ensino Superior de Rio Verde ESRIVER/Faculdade Unibrás, Rio Verde - GO em nome da Coordenação de Pesquisa e Inovação, ao Programa de Iniciação Científica - PIC, e a todo corpo de docentes e discentes do curso de Agronomia pelo apoio financeiro através de doações e colaboração na Fazenda de Ensino, Pesquisa e Extensão - FEPE, para execução deste trabalho de pesquisa.

\section{Referências}

AREVALO-HERNANDEZ, C.O.; PAIVA, A.Q.; MIZUKI, T.; ALMEIDA, A.J.G.; UZÊDA, M.C.; MATOS, E.N. Aspectos físicos da qualidade do solo sob sistemas agroflorestais e pastagem no sul da Bahia. Agrotrópica, v.28, n.1, p.55-64, $2016 . \quad$ https://doi.org/10.21757/01033816.2016v28n1p55-64

BAYAT, H.; SHEKLABADI, M.; MORADHASELI, M.; EBRAHIMI, E. Effects of slope aspect, grazing, and sampling position on the soil penetration resistance curve. Geoderma, v.303, p.150-164, 2017.

https://doi.org/10.1016/j.geoderma.2017.05.003

BENEVENUTE, P.A.N.; MORAIS, E.G.; SOUZA, A.A.; VASQUES, I.C.F.; CARDOSO, D.P.; SALES, F.R.; SEVERIANO, E.C.; HOMEM, B.G.C.; CASAGRANDE, D.R.; SILVA, B.M. Ecological Indicators, v.117, p.106647, 2020. https://doi.org/10.1016/i.ecolind.2020.106647

BERNARDO, S.; MANTOVANI, E.C.; SILVA, D.D.; SOARES, A.A. Manual de irrigação. 9. ed. Viçosa: UFV, 2019. 545p.

BERNARDO, S.; SOARES, A.A.; MANTOVANI, E.C. Manual de irrigação. 8.ed. Viçosa: Editora UFV, 2006. 625p

BISWAS, S.B.; IQBAL, M.T. Solar water pumping system control using a low cost ESP32 microcontroller. In: 2018 IEEE Canadian conference on electrical \& computer engineering (CCECE). Proceedings [... ]. IEEE, p.1-5, 2018. http://dx.doi.org/ 10.1109/CCECE.2018.8447749

BONDI, G.; O'SULLIVAN, L.; FENTON, O.; CREAMER, R .; MARONGIU, I.; WALL, D. Trafficking intensity index for soil compaction management in grasslands. Soil Use and Management, v.1-15, 2020. https://doi.org/10.1111/sum.12586

BORGES, W.L.B.; CALONEGO, J.C.; ROSOLEN, C.A. Impact of crop-livestock-forest integration on soil quality. Agroforestry Systems, p.1-9, 2019. https://doi.org/10.1007/s10457-018-0329-0

CABRAL FILHO, C.F.; CUNHA, F.N.; SILVA, N.F.; TEIXEIRA, M.B.; SANTOS, L.N.S.; VIEIRA, G.S. Water infiltration rate in distroferric red latosol under different cropping systems. Revista Brasileira de Agricultura Irrigada, v.11, n.3, p. $1371 \quad$ - 1381, 2017. https://doi.org/10.7127/rbai.v11n300555

CASTAGNARA, D.D.; OLIVEIRA, P.S.R.; BULEGON, L.G.; NERES, M.A.; PIANO, J.T.; ZOZ, T.; GERHARDT, I.F.S. Australian Journal of Crop Science, v. 9, n. 8, p.734-743, 2015.

COSTA, M.A.T.; TORMENA, C.A.; LUGÃO, S.M.B; FIDALSKI, J.; NASCIMENTO, W.G.; MEDEIROS, F.M. Resistência do solo à penetração e produção de raízes e de forragem em diferentes níveis de intensificação do pastejo. Revista Brasileira de Ciência do Solo, v.36, n.3, p.993-1004, 2012. http://dx.doi.org/10.1590/S010006832012000300029

COSTA, P.F.; OLIVEIRA, P.S.R.; PIANO, J.T.; TAFFAREL, L.E.; ARRÚA, M.A.M.; SARTO, 
M.V.I.M.; FERNANDES, S.S.L. Physical properties of a latosol eutrophic red under management systems after different winter crops successful by the soybean crop. African Journal of Agricultural Research, v.11, n.40, p.3929-3939, 2016. https://doi.org/10.5897/AJAR2016.11320

COUTO, W.H.; ANJOS, L.H.C.; WADT, P.G.S.; PEREIRA, M.G. Atributos edáficos e resistência de penetração em áreas de sistemas agroflorestais no sudoeste amazônico. Ciência Florestal, v.26, n.3, p.811-823, 2016. http://dx.doi.org/10.5902/1980509824210

CUNHA, J.L.X.L.; COELHO, M.E.H.; ALBUQUERQUE, A.W.; SILVA, C.A.; SILVA JUNIOR, A.B.; CARVALHO, I.D. Water infiltration rate in Yellow Latosol under different soil management systems. Revista Brasileira de Engenharia Agrícola e Ambiental, v.19, n.11, p.1021-1027, 2015.

http://dx.doi.org/10.1590/1807-

1929/agriambi.v19n11p1021-1027

FERNANDES, K.L.; RIBON, A.A.; TAVARES FILHO, J.; CUSTODIO, G.D.; BARROS, L.R. Influência do gerenciamento do tempo na modelagem da resistência de curvas à penetração de um Latossol sob diferentes usos e gerenciamento de pastagens e madeira nativa. Revista Árvore, Viçosa, v.40, n. 3, p. 519-527, $2016 . \quad$ https://doi.org/10.1590/0100$\underline{67622016000300015}$

FREITAS, G.A.; BENDITO, B.P.C.; SANTOS, A.C.M.; SOUSA, P.A. Diagnóstico ambiental de áreas de pastagens degradadas no município de Gurupi TO. Biota Amazônia, Macapá, v.6, n.1, p.10-15, $2016 . \quad$ https://doi.org/10.18561/21795746/biotaamazonia.v6n1p10-15

FURQUIM, L.C.; NUÑEZ, D. N.C.; SANTINI, J.M.K.; CABRAL, J.S.R.; SOUZA, E.J.; TEIXIEIRA, A.H.C.; BAYMA-SILVA, G.; NASCIMENTO, P. E. R.; STONE, L.F.; SOUCHIE, E.L.; BOLDRIN, M.C.F. Qualidade física, química e biológica do solo e sensoriamento remoto na recuperação de pastagens degradas através de sistemas integrados. Científic@-Multidisciplinary Journal, v.5, n.3, p.145-160, 2018.

https://doi.org/10.29247/2358-

260X.2018v5i3.p145-160
GAVA, R.; SILVA, E.E.; BAIO, F.H.R. Calibração de sensor eletrônico de umidade em diferentes texturas de solo. Revista Brasileira de Engenharia de Biossistemas, v.10, n.2, p.154-162, 2016. http://dx.doi.org/10.18011/bioeng2016v10n2p15 4-162

GOMES FILHO, R.R.; SANTOS, I.L.; PEDROTTI, A.; CARVALHO, C.M.; AGUIAR NETTO, A.O.; CARVALHO, L.L.S. Análise do comportamento de modelos para ajuste da velocidade de infiltração em diferentes usos de solo. Revista Brasileira de Agricultura Irrigada, v.12, n.4, p.2755-2760, 2018. https://doi.org/10.7127/rbai.v12n400971

GONÇALVES, F.C.; MORAES, M.H. Porosidade e infiltração de água do solo sob diferentes sistemas de manejo. Irriga, v.17, n.3, 2012. https://doi.org/10.15809/irriga.2012v17n3 p337

HABILI, J.M.; HEIDARPOUR, M. Application of the Green-Ampt model for infiltration into layered soils. Journal of Hydrology, v.25, n.527, p. 824832, 2015.

https://doi.org/10.1016/j.jhydrol.2015.05.052

JOSE, J.V.; REZENDE, R.; MARQUES, P.A.A.; GONÇALVES, A.C.A.; SOUZA, R.S. Variabilidade espacial de variáveis físico-hídricas de dois Latossolos da região noroeste do estado do Paraná. Irriga, v.17, n.2, 2012. https://doi.org/10.15809/irriga.2012v17n2p208

KOSTIAKOV, A.N. On the dynamics of the coefficient of water - percolation in soils and on the necessity for studying it from a dynamic point of view for purposes of ameliation. Trans. $6 t \mathbf{~} h$ comm. Moscou: Intern. Soc. Soil Sci., Part A., p.17-21, 1932.

MAGALHÃES, W.A, FREDDI, O.S; LANGE, A.; WRUCK, F.J.; SILVA, W.M.; SOARES, M.B. Atributos físicos-hídricos do solo no sistema integrado de produção com diferentes arranjos do componente florestal paricá. Pesquisa Agropecuária Brasileira, v.53, n.3, p.351-360, $2018 . \quad$ https://doi.org/10.1590/\$0100$\underline{204 \times 2018000300010}$

MAIA, S.M.F.; XAVIER, F.A.S.; OLIVEIRA, T.S.; MENDONÇA, E.S.; ARAUJO FILHO, J.A. Organic carbon pools in a Luvisol under agroforestry and conventional farming systems in the semi-arid 
region of Ceará, Brazil. Agroforestry Systems, v.71, n.2, p.127-138, 2007. https://doi.org/10.1007/s10457-007-9063-8

MARIA, L.S.; OLIVEIRA, P.P.G.; SILVA, M.S.; YAMASHITA, O.M. Contribuição dos sistemas de Integração Lavoura-Pecuária-Floresta (ILPF) no sequestro de carbono. Revista Espacios, v.38, n.31, p.13-17, 2017.

MARTINS, F.P.; SANTOS, E.L. Taxa de infiltração da água e a resistência do solo a penetração sob sistemas de uso e manejo. Acta Iguazu, v.6, n.4, p.28-40, 2017.

MORAES, A.G.L.; CARVALHO, D.F.; ANTUNES, M.A. H.; CEDDIA, M.B.; FLANAGAN, D. Steady infiltration rate spatial modeling from remote sensing data and terrain attributes in southeast Brazil. Geoderma Regional, v.20, p.e00242, 2020. https://doi.org/10.1016/i.geodrs.2019.e00242

MORAES, M.T.; DEBIASI, H.; CARLESSO, R.; FRANCHINI, J.C.; SILVA, V.R. Critical limits of soil penetration resistance in a rhodic Eutrudox. Revista Brasileira de Ciência do Solo, v.38, p.288-298, 2014. https://doi.org/ 10.1590/S0100-06832014000100029.

MORAIS, F. Infiltração - uma variável geomorfológica. Caderno de Geografia. v.22, n. 38, p.73-97, 2012.

NERES, M.A.; AMES, J.P. Novos aspectos relacionados à produção de feno no Brasil. Scientia Agraria Paranaensis, v.14, n.1, p.10-17, 2015. https://doi.org/10.18188/sap.v14i1.11138

R CORE TEAM. A language and environment for statistical computing. Vienna: R Foundation for Statistical Computing, 2016. Disponível em: https://www.r-project.org/. Acesso em: 03 ago 2020.

RIQUELME, A.M.; LUZ, L.H.B.P.; SILVA FILHO, E.P. Velocidade de infiltração de água em Latossolo vermelho-amarelo distrófico sob diferentes cultivos. Revista Brasileira de Ciências da Amazônia, v. 1, n. 1, 2012.

SANTOS, H.G.; JACOMINE, P.K.T.; ANJOS, L.H.C.; OLIVEIRA, V.A.; LUMBRERAS, J.F.; COELHO, M.R.; ALMEIDA, J.A.; ARAUJO FILHO, J.C.; OLIVEIRA, J.B.; CUNHA, T.J.F. Sistema brasileiro de classificação de solos. 5.ed. Brasília: Embrapa, 2018.

SANTOS, M.A.D.N.D.; PANACHUKI, E.; ALVES SOBRINHO, T.; OLIVEIRA, P.T.S.D.; RODRIGUES, D.B.B. Water infiltration in an ultisol after cultivation of common bean. Revista Brasileira de Ciência do Solo, v. 38, n. 5, p. 1612-1620, 2014. http://dx.doi.org/10.1590/S0100$\underline{06832014000500026}$

SHAH, S.N.; MOHSIN, T.; SHAHZAD, B.; GUOZHENG, Y.; SHAH, F.; SAIF, A.; MUHAMMAD, A.B.; SHAHBAZ, A.T.; ABDUL, H.; BIANGKHAM, S. Soil compaction effects on soil health and crop productivity: an overview. Environmental Science and Pollution Research, v.24, n.11, p.1005610067, 2017. https://doi.org/10.1007/s11356017-8421-y

SILVA FILHO, E.P. Velocidade de infiltração em área pastagem degradada e floresta natural no município de Porto Velho (RO). Revista francobrasileira de geografia, n.29, 2016. https://doi.org/10.4000/confins.11635

SILVA, N.F.; CUNHA, F.N.; TEIXEIRA, M.B.; SOARES, F.A.L.; VIDAL, V.M.; MORAIS, W.A. Reposição hídrica e adubação nitrogenada na cana-de-açúcar via gotejamento subsuperficial: cana-planta e cana-soca. Revista Brasileira de Agricultura Irrigada, v.11, n.6, p. 1862-1875, 2017. https://doi.org/10.7127/rbai.v11n600642

SILVA, N. F.; CUNHA, F. N.; CABRAL FILHO, F. R.; MORAIS, W. A.; CUNHA, E. S.; ROQUE, R. C.; ALVES, D. K. M.; Teixeira, M. B. Métodos para estimativa da infiltração de água em um Latossolo sob plantio direto e convencional. GI. Sci Technol, v.10, n.01, p.169-176, 2017.

SILVA, N.F.; CUNHA, F.N.; OLIVEIRA, R.C.; CABRAL FILHO, F.R.; TEIXEIRA, M.B.; CARVALHO, J.J. Características físico-hídricas de um Latossolo sobre diferentes sistemas de manejo. Revista Brasileira de Agricultura Irrigada, v.8, n 5, p.375390, 2014.

https://doi.org/10.7127/rbai.v11n600642

SILVA, W.M.; BIANCHINI, A.; CUNHA, C. A. Modelagem e correção da resistência à penetração do solo para variações na umidade e densidade do solo. Eng. Agríc. v.36, n.3, p. 449- 
459, 2016. https://doi.org/10.1590/1809-4430Eng.Agric.v36n3p449-459/2016

SOUSA, D.M.G.; LOBATO, E. (Ed.). Cerrado: correção do solo e adubação. 2. ed. Brasília, DF: Embrapa Informação Tecnológica; Planaltina, DF: Embrapa Cerrados, 2004. 416 p. il.

STOLF, R. Teoria e teste experimental de fórmulas de transformação dos dados de penetrômetro de impacto em resistência do solo. Revista Brasileira de Ciência do Solo, Campinas, v.15, p.229-235, 1991.

UNUIGBE, B.O.; OFEM, K.I.; ANTIGHA, N.R.B. Irrigation potential of Inuakpa in Odukpani local government of Cross river using Kostiakov model. Global Journal of Agricultural Sciences, v. 15, n.1, p.37-40, 2016. https://doi.org/10.4314/gjass.v15i1.7

VILARINHO, M.K.C.; KOETZ, M.; SCHLICHTING A.F. Determinação da taxa de infiltração estável de água em solo de cerrado nativo. Revista Brasileira de Agricultura Irrigada, v.7, n.1, 2013. https://doi.org/10.7127/rbai.v7n100097

WALLER, P.; YITAYEW, M. Soil Physics. In: Irrigation and Drainage Engineering. Springer, Cham, p.33-50. 2016. https://doi.org/10.1007/978-3-319-05699-9 3

ZHAO, Y.; WU, P.; ZHAO, S.; FENG, H. Variation of soil infiltrability across a 79-year chronosequence of naturally restored grassland on the Loess Plateau, China. Journal of Hydrology, v.504, p.94103, 2013. https://doi.org/10.1016/i.jhydrol.2013.09.039

ZHIPENG, L.; DONGHAO, M.; WEI, H.; XUELIN, L. Land use dependent variation of soil water infiltration characteristics and their scale-specif controls. Soil \& Tillage Research, v.178, p.139149, 2018.

https://doi.org/10.1016/j.still.2018.01.00 